\title{
The boron isotopic signature of serpentine from obducted ophiolites: mixture of fluids and tectonic implications.
}

\author{
CELINE MARTIN ${ }^{1}$, KENNET FLORES ${ }^{1,2}$, GEORGE \\ HARLOW $^{1}$, SAMUEL ANGIBOUST ${ }^{3}$, FLORENT HODEL $^{4}$ \\ AND GEORGE GUICE ${ }^{5}$ \\ ${ }^{1}$ American Museum of Natural History \\ ${ }^{2}$ CUNY - Brooklyn College \\ ${ }^{3}$ Institut de Physique du Globe de Paris, Sorbonne Paris Cité \\ ${ }^{4}$ Université de Franche-Comté \\ ${ }^{5}$ Smithsonian National Museum of Natural History \\ Presenting Author: cmartin@amnh.org
}

Obducted ophiolites commonly expose oceanic lithosphere slivers in suture zones. The few studies conducted specifically on the serpentinization of the ultramafic part of ophiolite mostly concluded that serpentinization was driven by seawater. Recent developments in tracking fluid source(s) in serpentinites using B isotopes have shown that seawater hydration yields serpentinites with $\delta^{11} \mathrm{~B}$ above $+10 \%$, while serpentinites with a $\delta^{11} \mathrm{~B}$ below $+10 \%$ have been hydrated by subducted crust-derived metamorphic fluids. Seventeen samples from well-characterized ophiolites in Guatemala, Brazil, and Iran have been analyzed for B isotopes. Samples from Guatemala and Iran are from fossil Supra Subduction Zones (SSZ), while samples from Brazil are from a fossil Ocean-Continent Transition (OCT).

Most of the samples display the typical pseudomorphic mesh matrix and bastite texture; two samples are lacking any specific textures, and three are made of green and white patches with mineralogy similar to each other. Nine of the samples studied here are either totally (both textures) or partially (one texture only) out of isotopic equilibrium, with $\delta^{11} \mathrm{~B}$ variations of up to 18 $\%$ within individual samples/textures. Among the samples with narrower $\delta^{11} \mathrm{~B}$ range (i.e., at isotopic equilibrium), serpentinites from fossil SSZ have $\delta^{11} \mathrm{~B}$ straddling $0 \%$, ranging from -7.7 to $+13.5 \%$. This indicates that seawater alone was not responsible for serpentinization of these ultramafic rocks, but rather either subducted crust-derived metamorphic fluids, or a mixture of seawater and subducted crust-derived metamorphic fluids, for the highest $\delta^{11} \mathrm{~B}$. Serpentinites from a fossil OCT (Brazil) have $\delta^{11} \mathrm{~B}$ ranging from +3.8 to $+23.2 \%$, mostly in agreement with serpentinization by seawater.

In conclusion, serpentinites from former OCT have $\delta^{11} \mathrm{~B}$ typical of serpentinites forming from seawater, while serpentinites from former SSZ have $\delta^{11} \mathrm{~B}$ representing a mixture of seawater and subducted crust-derived metamorphic fluids, in agreement with the recent suggestion that SSZ ophiolites possibly represent ancient forearc lithosphere. 